Canadian

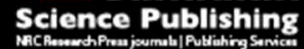

Canadian Journal of Chemistry Revue canadienne de chimie

\title{
Enzymatic Synthesis of 5-Amino Quinoline Oligomers and Evaluation of Their Free Radical Scavenging Activity
}

\begin{tabular}{|r|l|}
\hline Journal: & Canadian Journal of Chemistry \\
\hline Manuscript ID & cjc-2016-0210.R1 \\
\hline Danuscript Type: & Article \\
\hline Complete List of Authors: & $\begin{array}{l}\text { Bilici, Ali; Canakkale Onsekiz Mart Universitesi } \\
\text { geçibesler, ibrahim; Laboratory of Natural Product Research, Faculty of } \\
\text { Health Sciences, Bingol University; Laboratory of Natural Product Research, } \\
\text { Faculty of Health Sciences, Bingol University } \\
\text { Kaya, İsmet; Canakkale Onsekiz Mart Universitesi }\end{array}$ \\
\hline Keyword: & $\begin{array}{l}\text { enzymatic polymerization, HRP, 5-aminoquinoline, antioxidant activity, } \\
\text { DPPH }\end{array}$ \\
\hline & \\
\hline
\end{tabular}

SCHOLARONE ${ }^{\text {m }}$

Manuscripts 


\title{
Enzymatic Synthesis of 5-Amino Quinoline Oligomers and Evaluation of Their Free Radical Scavenging Activity
}

\author{
Ali Bilici ${ }^{a} *$ İbrahim Halil Geçibesler ${ }^{\text {b }}$, İsmet Kaya ${ }^{a}$ \\ ${ }^{\mathrm{a} C}$ Canakkale Onsekiz Mart University, Faculty of Sciences and Arts, Department of Chemistry, Polymer \\ Synthesis and Analysis Lab. 17020 Çanakkale, Turkey \\ ${ }^{\mathrm{b}}$ Laboratory of Natural Product Research, Faculty of Health Sciences, Bingol University, 12000 Bingol, Turkey
}

\begin{abstract}
The compound 5-aminoquinoline (AQ) was treated with horseradish peroxidase (HRP)/ $\mathrm{H}_{2} \mathrm{O}_{2}$ in a reaction medium containing dioxane/phosphate buffer mixture (70:30). The products (OAQ) having a degree of polymerization ranging from 4 to 12 were obtained. ${ }^{1} \mathrm{H}-\mathrm{NMR}$, FTIR, UV-Vis, SEM, TG-DTA, DSC, XRD analysis and conductivity measurements were conducted for characterization of OAQ. As compared to monomer, OAQ showed higher thermal stability. $46 \%$ of the initial weight of the OAQ remained after heating to $1000{ }^{\circ} \mathrm{C}$. The antioxidant efficiencies of monomer and oligomer were evaluated by the typical spectrophotometric method, such as the bleaching of 2,2-diphenyl-1-picrylhydrazyl (DPPH) radicals. OAQ showed improved DPPH activity as compared with the AQ monomer.
\end{abstract}

Keywords: enzymatic polymerization, HRP, 5-aminoquinoline, antioxidant activity, DPPH To whom all correspondence should be addressed.

Phone: +902862180018 Fax:+902862180533ｅ-mail:alibilici66@hotmail.com, alibilici@comu.edu.tr 


\section{Introduction}

The oxidative polymerization is a commonly used method to obtain the various functional polymers. The different class aromatic polymers including polycarbazole, polyfluorene, polyaniline, polyantracene, polythiophene, polynaphthole etc. have been synthesized by this process (1). One class of such polymers is polyquinoline and its derivatives. Quinolines and poly(quinoline)s have been reported to have high electron mobilities, good thermal and oxidative stabilities, and high photoluminescence efficiencies. Furthermore, they possess good film forming properties, which is crucial for their use in optical purpose (2). Amino quinoline monomers have been also reported to have wide applicability towards pharmacological, antihypertensive, antimalarial, antibacterial and antioxidant agents (3).

Althought, the synthesis and characterization of quinolone copolymers, blends and composites are studied widely, the synthesis and the properties of quinolone homopolymers have been less investigated $(2,4)$. Ragimov and co-workers studied the oxidative polymerization of 8-hydroxy quinoline in alkaline medium in the presence of air oxygen. The product isolated was reported to be semiconductor and also antibacterial agent (5). The polymerization of 8-hydroxy quinoline is also studied by Yomamato and co-workers in catalytic reaction medium (6). Horse radish peroxidase and $\mathrm{H}_{2} \mathrm{O}_{2}$ were used as catalyst and oxidant, respectively. $\mathrm{C} 2$ and $\mathrm{C} 7$ positions of quinoline ring were suggested as the polymerization sites. The polymer obtained was blue light emitter. Another quinoline monomer, 2-methyl quinoline-8-ol was polymerized in alkaline medium with $\mathrm{NaOCl}$ (oxidant). The complexes of polymer with different metal ions were also synthesized (7).

Recently, we studied the oxidation of hydroxy functionalized quinoline monomers, 4hydroxy quinoline (8), 5- hydroxy quinolone (9), 6- hydroxy quinoline (10) and 8- hydroxy quinolone (11) in various polymerization medium. The physical and chemical properties of polymerization products were reported. 
On the other hand, the oxidation of various aminoquinoline monomers including 5AQ (12), 6AQ (13), 8AQ (4) was also investigated. The obtained products were reported to be oligomers.

In our last work, the oxidation of $\mathrm{AQ}$ was presented and $\mathrm{AuCl}_{3}$ solution (14) was used as the oxidant as the reaction medium. The obtained nanocomposite exhibited high thermal stability: $5 \%$ of the decomposition temperature of composite took place at $643{ }^{\circ} \mathrm{C}$. This composite was highly crystalline and green light emitter.

In here, it was reported the enzyme-catalyzed oxidation reaction of 5-amino quinoline. The product obtained were characterized with the different analytical techniques: UV-visible (UVVis) spectroscopy, Fourier transform infrared (FT-IR) spectroscopy, ${ }^{1} \mathrm{H}-\mathrm{NMR}$, scanning electron microscopy (SEM), thermogravimetric-differantial thermal analysis (TG-DTA), DSC and solid state conductivity measurements. The antioxidant capacity of monomer and oligomer were also evaluated by examining the scavenging effect on 2,2-diphenyl-1-picryl hydrazyl (DPPH) assay.

\section{Experimental}

\subsection{Materials}

HRP was provided from Sigma Chemical Company and had a specific activity of 259 purpurogallin units/mg and $\mathrm{RZ}=3.0$. The other chemicals were purchased from Merck and they were used as received.

\subsection{Characterization techniques}

The infrared and ultraviolet-visible (UV-Vis) spectra were measured by Perkin Elmer FT-IR Spectrum One and Analytikjena Specord 210 plus, respectively. ${ }^{1} \mathrm{H}$ NMR spectrum (Bruker Avance DPX-400 MHz) was recorded at $25^{\circ} \mathrm{C}$ using deuterated DMSO as solvent. Tetramethylsilane (TMS) was used as internal standard. Thermal data were obtained using a Perkin Elmer Diamond Thermal Analysis. The TG-DTA measurements were made between 
$15^{\circ}$ and $1000{ }^{\circ} \mathrm{C}$ (in $\mathrm{N}_{2}$, rate $10^{\circ} \mathrm{C} \mathrm{min}^{-1}$ ). DSC analyses were performed by using a PerkinElmer Pyris Sapphire DSC instrument between $25-420{ }^{\circ} \mathrm{C}$ under nitrogen at a heating rate of $10{ }^{\circ} \mathrm{C} \min ^{-1}$ in an aluminum pan (in $\mathrm{N}_{2},{ }^{\circ} \mathrm{C} \min ^{-1}$ ). Conductivity measurements were conducted on a Keithley 2400 electrometer, using four-point probe technique. The doping process was performed by exposure of the pressed oligomers to iodine vapour at atmospheric pressure in a desiccator at $25^{\circ} \mathrm{C}$. The field emission-scanning electron microscope (FE-SEM) (Jeol JSM-7100F Schottky field) was used to examine the surface morphology of OAQ. Bruker micro flex LT model matrix assisted laser desorption ionization time-of-flight mass spectroscopy (MALDI-TOF MS) was used for determination of molecular weight of product. A $\alpha$-cyano-4-hydroxycinnamicacid was used as matrix. XRD patterns were obtained using a PAN analytical Empyrean Model X-ray diffractometer with $\mathrm{Cu} \mathrm{K} \alpha$ radiation at a wavelength of $1.54 \AA$ over a $2 \Theta$ range from $5^{\circ}$ to $90^{\circ}$. The scan speed was $4^{\circ} \mathrm{min}^{-1}$.

\subsection{Oxidation process}

The oxidation process was performed as given in below (15): $5 \mathrm{mmol}$ monomer and $7.5 \mathrm{mg}$ HRP were dissolved in the $35 \mathrm{~mL}$ dioxane and $15 \mathrm{~mL}$ sodium phosphate buffer mixture. The reaction mixture was continuously stirred. After the addition of $\mathrm{H}_{2} \mathrm{O}_{2}(5 \%)$, the color of reaction solution was converted from pale white into brown. The reaction was stirred for 24 hours at $25^{\circ} \mathrm{C}$ at $180 \mathrm{rpm}$. After that, this mixture was dropped into a large amount of water. The precipitates formed were collected by filtration, washed with water to remove any residual enzyme, phosphate salt, and finally washed with ethanol to remove unreacted monomer and then dried in a vacuum oven for $24 \mathrm{~h}$. The polymerization process is outlined in Figure 1.

\section{Insert Figure 1 here}




\subsection{Antioxidant activity of the $A Q$ and $O A Q$ product using the DPPH free radical method}

Antiradical efficiency of compound AQ, product OAQ and reference compound (used as Trolox) on DPPH (2,2-diphenyl-1-picrylhydrazyl) radical was evaluated according to the procedures described by Sanchez-Moreno (16) and Cetin and Gecibesler 2015 (17) with minor modifications. $20 \mathrm{mg}$ DPPH was dissolved in $100 \mathrm{~mL}$ ethanol at a final concentration of about $5 \times 10^{-5} \mathrm{M}$ and it was stored in an amber bottle. Standard solutions of antiradical assay substances were prepared at a concentration of $1 \mathrm{mg} / \mathrm{ml}$ in the ethanol solvent. Prior to analysis each test tube covered with aluminum foil. An aliquot of these solutions $(1 \mathrm{~mL})$ of different concentrations $(2.25-180 \mu \mathrm{g} / \mathrm{mL})$ was added to $1 \mathrm{ml} \mathrm{DPPH}$ solution. The decrease in the absorbance at $517 \mathrm{~nm}$ was monitored using a Perkin-Elmer UV-Vis spectrophotometer, until the reaction reached the steady state. After the reaction, the DPPH concentration $([\mathrm{DPPH}])$ in the reaction medium was determined using the following linear regression obtained from the calibration curve: Absorbance $_{517}=0.1632 \times[\mathrm{DPPH}]+0.0443\left(\mathrm{R}^{2}=0.999\right)$. After reaction completed, the percentage of remaining DPPH $\left(\% \mathrm{DPPH}_{\mathrm{R}}\right)$ in the reaction medium was calculated using the concentration of DPPH at the initial $[\mathrm{DPPH}]_{\mathrm{I}}$ and at the end $[\mathrm{DPPH}]_{\mathrm{L}}$ of reaction as follows: \% $\mathrm{DPPH}_{\mathrm{R}}=\left([\mathrm{DPPH}]_{\mathrm{L}} /[\mathrm{DPPH}]_{\mathrm{I}}\right) \times 100$.

To calculate the $\mathrm{EC}_{50}$ value, meaning the concentration of antiradical needed to decrease by $50 \%$ the initial DPPH radical concentration, a calibration curve was plotted using the \% $\mathrm{DPPH}_{\mathrm{R}}$ against concentrations of samples. Using the linear regression models obtained from the curves, the amount of sample to inhibit the initial DPPH concentration by $50 \%$ was calculated and stated as $\mathrm{EC}_{50}(\mu \mathrm{g}$ sample/mg DPPH) (16). The antiradical efficiency (AE) is defined as $\mathrm{AE}=1 / \mathrm{EC}_{50} \times \mathrm{TEC}_{50}$ where $\mathrm{TEC}_{50}$ was the time needed to reach a steady state when using an initial concentration of antioxidant equal to the $\mathrm{EC}_{50}$ concentration (16). All experiments were performed in two replicates. 


\subsection{Statistical analysis}

Determination of antiradical efficiency assays were performed in duplicate and the mean values were calculated. The data were subjected to analysis of variance and Duncan's multiple range tests were employed to gauge differences between means. A significant difference was judged to exist at a level of $p<0.05$.

\section{Results and discussion}

OAQ was prepared by $\mathrm{HRP} / \mathrm{H}_{2} \mathrm{O}_{2}$ oxidation of AQ in the phosphate buffer/dioxane mixture. The oligomeric product was obtained in $78 \%$ yield as a brown powder. The polymerization was confirmed by visual assessment and UV-Vis analysis. The color of reaction mixture was changed from pale white to a dark brown color during oxidant addition, indicating the synthesis of OAQ. Through experiment, the reaction mixture seemed homogenous. The precipitated product was soluble in polar organic solvents including THF, DMF, DMSO and it was insoluble in toluene and water. Especially, DMF dissolved all the product. The gel permeation chromatography (GPC) measurements showed bimodal distribution. The first fraction was low molecule weight $\left(\mathrm{M}_{\mathrm{n}}: 4500 \mathrm{~g} \mathrm{~mol}^{-1}, \mathrm{M}_{\mathrm{w}}: 6000 \mathrm{~g} \mathrm{~mol}^{-1}\right.$, PDI: 1.33). It formed $65 \%$ of OAQ. But, the second fraction formed was $35 \%$ of OAQ and it had a higher molecular weight $\left(\mathrm{M}_{\mathrm{n}}: 29000 \mathrm{~g} \mathrm{~mol}^{-1}, \mathrm{M}_{\mathrm{w}}: 21000 \mathrm{~g} \mathrm{~mol}^{-1}\right)$ than the first fraction. PDI of this fraction was also larger (1.38). The average molecular weights and polydispersity index of OAQ were determined as $\mathrm{M}_{\mathrm{w}}=7000 \mathrm{~g} \mathrm{~mol}^{-1}, \mathrm{M}_{\mathrm{n}}=5100 \mathrm{~g} \mathrm{~mol}^{-1}, \mathrm{M}_{\mathrm{w}} / \mathrm{M}_{\mathrm{n}}=1.37$ (Fig. 2a). Maldi-TOF-MS analysis was also used to verify the molecular weight of OAQ (Fig. 2b). The mass difference between each group of adjacent ion peaks averages was about $148 \mathrm{Da}$. This value was higher than mass of repeating monomer units. It is expected that mass difference between peaks representing various oligomeric structure should be about 142 Da (144-2H). Note that there is still $6 \mathrm{Da}$ of unknown elements. This difference may be attributed to the nature of oxidation process. In the other word, limited hydrolysis of product or hydroxylation 
of aromatic rings in some extent may be cause for formation of $-\mathrm{NH}_{2} ;-\mathrm{NO} ; \mathrm{NH} ;=\mathrm{NO}_{2} ;=\mathrm{O}$ groups (18). The peaks at $\mathrm{m} / \mathrm{z}$ values $592(\mathrm{n}=4), 740(\mathrm{n}=5), 889(\mathrm{n}=6), 1036(\mathrm{n}=7), 1184$ $(n=8), 1332(n=9), 1480(n=10), 1628(n=11)$ and $1776(n=12)$ were observed. There were weak molecular ion peaks at m/z 1776 that could be taken as molecular weight, assigning that oxidation product had degree of polymerization of about 12 .

\section{Insert Figure 2 here}

This difference between measurement results (GPC and Maldi-TOF-MS) were also reported in the literature and it was attributed to different reasons including low ionization potential of MALDI TOF-MS or its sensitivity and issues associated with the dynamic range. $(8,19,20)$. The structure of oxidation products was elucidated by UV-Vis, FT-IR and ${ }^{1} \mathrm{HNMR}$ techniques. For comparison, monomer spectra were also recorded for all analysis. The UVVis spectrum of AQ revealed two bands centered at 364 and 480nm. (Figure 3a) (16).

\section{Insert Figure 3 here}

On the other hand, OAQ displayed similar but red shifted absorption bands which are centered at 380, $493 \mathrm{~nm}$ (Fig. 3b). The red shifted absorption band and an absorption tail from 400 to $750 \mathrm{~nm}$ could be attributed to a more extended conjugating system (21).

Tauch gap is often used to characterize the optic band gap of the semiconductors $(22,23)$. This equation is described as follows:

$\mathrm{Ahv}=\mathrm{An}(\mathrm{hv}-\mathrm{Eg})$

here $\alpha, \mathrm{A}, \mathrm{v}, \mathrm{h}, \mathrm{Eg}$, and $\mathrm{n}$ are linear absorption coefficient, energy-independent constant, frequency, Planck constant, energy band gap and a constant related to the type of optical transitions, respectively. $\mathrm{n}$ takes the values $1 / 2,3 / 2,2$ and 3) for allowed direct, allowed indirect, forbidden direct and forbidden indirect transitions, respectively. Fig. 3c shows the relationship between $\ln (\alpha \mathrm{hv})$ and $\ln (\mathrm{hv}-\mathrm{Eg})$ values. The optical band gap was determined as 
$3.5 \mathrm{eV}$ by extrapolation the straight line portion of the curve to zero absorption coefficient value (Fig. 3c). Fig. 4 shows FTIR spectra of monomer and oligomer.

\section{Insert Figure 4 here}

FTIR spectrum of OAQ (Fig. 4b) showed all the characteristic bands of quinoline ring between 650 and $1600 \mathrm{~cm}^{-1}$. The peaks observed at 1570 and $1495 \mathrm{~cm}^{-1}$ were characteristic of the $\mathrm{C}=\mathrm{C}$ stretching of the quinoid and benzenoid rings $(4,14)$. The bands at 1313 and $795 \mathrm{~cm}^{-1}$ were related to $\mathrm{C}-\mathrm{N}$ stretching of amine groups and aromatic $\mathrm{C}-\mathrm{H}$ bending out-of plane bending vibrations, respectively (21). The broadened bands between 3250$3500 \mathrm{~cm}^{-1}$ indicated the conversion of part of $\mathrm{N}-\mathrm{H}$ bondings into $\mathrm{N}-\mathrm{C}$ bondings by couplings $(4,21)$. The broadened IR peaks also assigned the coexistence of different coupling modes in the chains.

As known, the oxidation of aromatic amine and phenol monomers by oxireductases follows a radicalic pathway $(15,18)$. The resonance forms of AQ were presented in the Figure 5.

\section{Insert Figure 5 here}

This figure helps us to estimate the possible polymerization sites. As seen from this figure, the participations of monomer units to each other via C3, C5, C6 and C8 carbons seems more possible. ${ }^{1} \mathrm{H}-\mathrm{NMR}$ spectra of $\mathrm{AQ}$ and $\mathrm{OAQ}$ are given in the Figure 6.

\section{Insert Figure 6 here}

The multiple proton signals of OAQ from 6-8 ppm assigned presence aromatic protons having different chemical surroundings (Fig. 6b). This spectrum assigned that monomer units are linked to each other via mainly $\mathrm{C} 3, \mathrm{C} 5, \mathrm{C} 6, \mathrm{C} 8$ carbons in a random rank. The further assignments for precise structure seemed difficult due to regio-random chain structure of OAQ. However, the intensities of $\mathrm{Ha}(6.76 \mathrm{ppm})$ and $\mathrm{Hg}(6.04 \mathrm{ppm})$ protons and of AQ were highly diminished after polymerization. As a result, it was possible to say that monomer couplings took place via mainly $\mathrm{Ha}$ and $\mathrm{Hg}$ eliminations. Thermal stability of the product was 
evaluated by TGA/DSC thermoanalytical methods. Figure 7 belongs to TG-DTG-DTA curves of OAQ.

\section{Insert Figure 7 here}

The DTG curve of OAQ assigned three steps of mass loss. The decomposition maxima determined from DTG curve were 299,405 and $962^{\circ} \mathrm{C}$. TG curve assigned a gradually decomposition of OAQ. The first decomposition range was between 50 and $155^{\circ} \mathrm{C}$ was due to elimination solvent and dopant ion molecules in the oligomer chains. Mass loss measured in this range was $7.4 \%$. The second decomposition stage was observed between ca 200 to 500 ${ }^{\circ} \mathrm{C}$. This was attributed to the decomposition of oligomeric chains in the product $(\mathrm{C}-\mathrm{C}$ and $\mathrm{C}$ $\mathrm{N}$ type linkages). The last decomposition range was between 600 to $1000^{\circ} \mathrm{C}$ which was attributed to cleavage of aromatic rings 20 and $50 \%$ decomposition temperatures of OAQ were found to be 393 and $966^{\circ} \mathrm{C}$, respectively. The char residue at $1000^{\circ} \mathrm{C}$ was found to be $45.86 \%$. This gradually decompositions assigned to the existence of regio-random polymerization product and side reactions developing throughout oxidative thermal treatment such as cross-linkings (24). Figure 8 belongs to DSC curve of OAQ.

\section{Insert Figure 8 here}

The endothermic effects were observed at 170 and $220{ }^{\circ} \mathrm{C}$. These values were harmony with DTG curves of OAQ. The glass transition temperature and melting point of the OAQ could not be determined from DSC analyses. The endothermic effects observed were attributed to the decomposition of oligomeric chains. Figure 9 shows X-ray diffraction spectra of AQ and OAQ.

\section{Insert Figure 9 here}

AQ exhibited sharp diffraction peaks between 10.85 and $29.73^{\circ}$ (Fig. 9a). As compared to AQ, OAQ exhibited broad diffraction peaks between $10^{\circ}$ and $30^{\circ}$ due to the parallel and perpendicular periodicity of the oligomer chains (25). XRD pattern showed low crystallinity 
due to the repetition of benzenoid and quinoid rings in chains. The strongest diffraction peaks of AQ and OAQ were observed at the same Bragg angles $\left(25^{\circ}\right)$. This similarity assigned that OAQ consists of AQ repetitive units (26-28). The oxidation of the other quinoline monomers was studied and the similar diffraction spectra were obtained (8-11). The morphology of product was investigated by SEM analysis. For comparison, the SEM images of AQ monomer were also recorded in the similar conditions. Figure 10 belongs the SEM images of AQ with the different magnifications. As seen these figures, the particles were unhomogeneous and not so well-ordered structure and shape. However, OAQ exhibited almost spherical structure with diameters ranging from 1-10 $\mu \mathrm{m}$ (Fig 11a, b and c).

\section{Insert Figure 10 and 11 here}

Nano-structures were detected as the SEM images were recorded at the higher magnifications (Fig 11d). The oxidative polymerization aromatic amine and hydroxyl compounds yields usually particles with the inhomogeneous and irregular structures (29, 30). However, enzymatic polymerization of AQ dioxane/phosphate system presented microspheres with the relatively regular shaped. The microspheres formation mechanism for OAQ is not clearly understood. The oxidative polymerization of aromatic monomers including 4-methyl catechol (31) and tyramine (32) by HRP was conducted in similar experimental conditions without use any stabilizer and the regular microparticle formation were reported in these studies. The microparticle formation is explained by self-assembly process in these studies. As known that the secondary interactions (hydrogen bonding and electrostatic interactions) are responsible for the formation of self-assemblation of the molecules (33).

Hydrogen bonding between neighboring OAQ chains is an important factor, which can stabilize the supramolecular structures of OAQ (34). In addition, possible ring hydroxylation during the oxidation and ionic bonding between such groups may be cause the same effect. 
The electrical conductivity of OAQ was determined by four-point-probe technique at room temperature both in doped and undoped forms. For this, the pressed OAQ powders exposed to iodine vapors for 24 hours. The conductivity of virgin product was found to be smaller than $10^{-11} \mathrm{~S} \mathrm{~cm}^{-1}$. After doping, the conductivity of OAQ didn't increase importantly. $\left(3.5 \times 10^{-9} \mathrm{~S}\right.$ $\mathrm{cm}^{-1}$ ) These values were relatively small as compared to quinoline homopolymers reported before $(9,10)$ and harmony with the wide band gap of OAQ measured $(3.5 \mathrm{eV})$. The low conductivity of OAQ may be attributed mainly to its low molecular weight and nonconjugated structure.

Aromatic amine monomers are known as antioxidants and are excellent hydrogen donors (35). It has been reported aromatic amine polymers such as polyaniline, poly(metoxyaniline), polypyrolle, polyaniline sulphonic acid, poly-N-methyl aniline, poly- $p$-phenylene diamine have high antioxidant properties (36-38). The polymeric antioxidants have some advantages such as high thermal stability, low volatility, good proccesability and high compatibility as compared to their corresponding analogues with the lower molecular weights (39).

Therefore, antioxidant capacities of the AQ and OAQ were evaluated in this study. For screening the antiradical efficiencies, DPPH radical scavenging assay is a rapid and convenient technique. According to this assay, the violet-colored DPPH free radical with the odd electron gives a strong absorption maximum in the visible region at $\lambda_{\max } 517 \mathrm{~nm}$. This the violet color returns to yellow when such odd electron of DPPH radical conjugates with a hydrogen to form the reduced DPPH-H. This color change is stoichiometric, where the degree of discoloration is proportional to the scavenging potential of the tested substance i.e. low absorbance refers to remarkable free radical scavenging potential. Figure 12 picturized the decrease of the DPPH free radical concentration in the case of compound AQ and product OAQ or reference antioxidant standard (Trolox) added. As shown in Figure 12, the monomer AQ, product OAQ and trolox were reduced in different degrees of the DPPH free radical in 
medium time-dependent manner. By $68.45 \%$ DPPH radical quenching was observed in the presence of the product OAQ at a concentration of $180 \mu \mathrm{g} / \mathrm{mL}$, while DPPH radical was quenched by monomer AQ with a ratio of $53.88 \%$ of at corresponding concentration after 24 hours, as compared to $94.89 \%$ quenched by a standard antioxidant trolox at the same conditions. In order to quantitatively compare the antiradical power of the tested substances was calculated as the antiradical efficiency (AE). The results recorded in Table 1 revealed that the monomer AQ and oligomer showed variable degrees of antiradical efficiency. The results point to a significantly higher $(p<0.05)$ antiradical efficiency of oligomer OAQ $\left(2.238 \times 10^{-3}\right.$ $\pm 0.02)$ compared to monomer AQ $\left(1.076 \times 10^{-3} \pm 0.03\right)$ except trolox $\left(4.719 \times 10^{-3} \pm 0.05\right)$, while the AE value for oligomer $\mathrm{OAQ}$ is about 2-times higher than the AE value for monomer $\mathrm{AQ}$, which is statistically significant (Table1).

The antioxidant ability of any compound are related to different factors such as its electronic structure and its ability to abstract or donate hydrogen atoms or the ionization ability of the reactive groups in the structure, or the potential for stabilization of the resulting radical by charge delocalization (40). It was reported that free radical scavenging activities of 8-hydroxy quinolone (40) and lignin polymers (41) have been increased with the increasing molecular weight and the extending $\pi$-polyconjugated systems. Therefore, it is possible to mean that the antioxidant power of OAQ is enhanced by the presence of extended $\pi$-conjugation systems as well as the presence of numerous reactive groups.

\section{Conclusion}

Enzyme catalyzed oxidative oligomerization of AQ was achieved by $\mathrm{H}_{2} \mathrm{O}_{2} / \mathrm{HRP}$. Maldi-TOFMS analysis assigned to the presence of twelve repeating units in the oxidation product. Spectral analysis indicated that OAQ chains were composed of a mixture of C-C and C-N units and monomer units are linked to each other in regio-random rank. Optic band gap of OAQ was found to be $3.5 \mathrm{eV}$. The conductivity value of OAQ was found to be $10^{-9} \mathrm{~S} / \mathrm{cm}^{-1}$ for 
doped state. The antiradical efficiencies of OAQ and AQ were found to be $2.238 \times 10^{-3} \pm 0.02$ and $1.076 \times 10^{-3} \pm 0.03$, respectively.

\section{Acknowledgement}

This work is financially supported by TUBITAK Grants Commission (Project no: TBAG113Z265).

\section{Compliance with ethical standards}

Conflict of interest The authors declare that they have no conflict of interest.

\section{References}

1) Bilici, A.; Doğan, F.; Yıldırım, M.; Kaya İ. Mater. Chem. Phys. 2013, 140, 66-74.

2) Kimyonok, A.; Wang, X.Y.; Weck, M. J. Macromol. Sci., Polym. Rev. 2006, 46, 47-77.

3) Brahmayya, M.; Rao, B.V.; Viplavaprasad, U.; Rao, B.M.V.; Babu, K.R.; Babu, B.K.; Rajkumara, K.; Praveen, C.; Giribabud, N.; Vijaya, M.; Padmarao, C.V.; Ra, N.S. J Appl.Pharm.Sci. 2012, 2, 41-44.

4) Li, X.G.; Huang, M.R.; Hua, Y.M.; Zhu, M.F; Chen, Q. Polymer, 2004, 45, 46934704.

5) Ragimov, A.V.; Mamedov, B.A.; Mustafaeva, Sh.I. Polymer, 1989, 30, 1851-1855.

6) Yamamoto, T.; Yamaguchi, I. Polym. Bull. 2003, 50, 55-60.

7) Kaya, İ.; Çetiner, A.; Saçak, M. J. Macromol. Sci. Pure Appl. Chem., 2007, 44, 463-468.

8) Bilici, A.; Doğan, F.; Yıldırım, M.; Kaya İ. J. Phys. Chem. C, 2012, 116, 19934-19940.

9) Bilici, A.; Doğan, F.; Yıldırım, M.; Kaya İ. React. Funct. Polym. 2011, 71, 675-683.

10) Doğan, F.; Bilici, A.; Yıldırım, M.; Kaya İ. Sci. Adv. Mater., 2014, 6, 1957-1964.

11) Doğan, F.; Kaya, İ.; Temizkan, K. J. Macromol. Sci., Pure Appl. Chem., 2014, 51, 948961.

12) El-Rahman, H.A.A. J. Appl. Electrochem. 1997, 27, 1061-1068. 
13) Stevic, M.C.; Ciric-Marjanovic, G.; Marjanovic, B.; Ignjatovic, L.M.; Manojlovic, D. J. Electrochem. Soc., 2012, 159, G151-G159.

14) Bilici, A.; Ayten, B.; Kaya İ. Synth. Met. 2015, 201, 11-17.

15) Yamaguchi, I.; Yamamoto, T. React. Funct. Polym. 2004, 61, 43-52.

16) Sánchez-Moreno, C.; Larrauri, J.A.; Saura-Calixto, F. J. Sci. Food Agric., 1998, 76, 270276.

17) Cetin, A.; Geçibesler, I. H. J Appl. Pharm. Sci. 2015, 5, 120-126.

18) Shumakovicha, G.; Streltsova, A.; Gorshina, E.; Rusinova, T.; Kurova, V.; Vasil'eva, I.; Otrokhov, G.; Morozova, O.; Yaropolov, A. J. Mol. Catal. B: Enzym. 2011, 69, 83-88.

19) Iwahara, K.; Honda, Y.; Watanabe, T.; Kuwahara, M. Appl. Microbiol. Biotechnol. 2000, 54,104-111.

20) Xu, P.; Kumar, J.; Samuelson, L.; Cholli, A.L. Biomacromolecules, 2002, 3, 889-893.

21)Li, X.G.; Hua, Y.M.; Huang, M.R. Chem. Eur. J., 2005, 11,4247-4256.

22) Tauc, J. Mater. Res. Bull. 1968, 3, 37-46.

23) Bhatt, R.; Bhaumik, I.; Ganesamoorthy, S.; Karnal, A.K.; Swami, M.K.; Patel, H.S.; Gupta, P.K. Physics Status Solidi A, 2012, 209, 176-180.

24) Li, X.G.; Duana, W.; Huang, M.R.; Yang, Y.L.; Zhao, D.Y. Polymer, 2003, 44, $6273-$ 6285.

25) Mostafaei, A.; Zolriasatein, A. Prog. Nat. Sci. Mat. Int. 2012, 22, 273-280.

26) Li, X.G.; Liu, Y.W.; Huang, M.R.; Peng, S.; Gong, L.Z.; Moloney, M.G. Chem. Eur. J., 2010, 16, 4803-4813.

27) Li, X.G.; Huang, M.R.; Duan, W.; Yang, Y.L. Chem. Rev., 2002, 102, 2925-3030.

28) Li, X.G.; Huang, M.R.; Yang, Y. Polymer, 2001, 42, 4099-4107.

29) Bilici, A.; Kaya, İ.; Yıldırım, M.; Doğan, F. J. Mol. Catal. B: Enzym., 2010, 64, 89-95.

30) Bilici, A.; Kaya, İ.; Yıldırım, M. Eur. Polym. J., 2011, 47, 1005-1017. 
31) Kawakita, H. Science and Technology 2012, 2, 25-29.

32) Kawakita, H.; Yoshimura, Y.; Ohto K. Ind. Eng. Chem. Res., 2010, 49, 11582-6.

33) Bilici, A.; Doğan, F.; Yıldırım, M.; Kaya İ. Mat. Chem. Phys., 2013, , 66-74.

34) Sapurina, I.; Stejskal, J. Polym Int, 2008, 57: 1295-1325 .

35) Gizdavic-Nikolaidis, M.; Jadranka, T.S.; Bowmaker, G.A.; Cooney, R.P.; Kilmartin, P.A. Synth. Met., 2004, 140, 225-232.

36) Gizdavic-Nikolaidis, M.; Travas-Sejdic, J.; Bowmaker, G.A.; Cooney, R.P.; Thompson, C.; Kilmartin, P.A. Curr. Appl. Phys., 2004, 4, 347-350.

37) Guimarda, N.K.; Gomez, N.; Schmidt, C.E. Prog. Polym. Sci. 2007, 32 , 876-921.

38) Lakouraj, M.M.; Zare, E.N.; Moghadam, P. N. Adv. Polym. Tech., 2014, 33, doi: 10.1002/adv.21385.

39) Zheng, K.; Zhang, L.; Gao, Y.; Wu, Y.; Zhao, W.; Cui, Y. J. Appl. Polym. Sci., 2015, $132,41591-90$.

40) Ncanana, S.; Burton, S. J. Mol. Catal. B: Enzym., 2007, 44, 66-71.

41) Riley, PA. Int. J. Biochem. Cell Biol., 1997, 29 , 1235. 


\section{CAPTIONS OF TABLE and FIGURES}

Table 1. $\mathrm{EC}_{50}$ values, antiradical efficiencies (AE) and times to reach the steady state $\left(\mathrm{TEC}_{50}\right)$ of monomer AQ, product OAQ and trolox.

Figure 1. The general oxidation scheme for AQ monomer. In this general presentation, possible coupling sites (aromatic C-C and C-N-C bondings) are given in Figure 5.

Figure 2. GPC profile (a) and MALDI-TOF-MS spectra (b) of OAQ.

Figure 3. UV-Vis spectra of AQ (a), OAQ (b) Tauch plot for OAQ(c).

Figure 4. FT-IR spectra of AQ (a) and OAQ (b).

Figure 5. Possible resonance forms of AQ.

Figure 6. $\quad{ }^{1} \mathrm{HNMR}$ spectra of AQ (a) and OAQ (b).

Figure 7. TG/DTG/DTA curves of OAQ.

Figure 8. DSC profile of OAQ.

Figure 9. XRD spectra of AQ (a) and OAQ (b).

Figure 10. SEM images of $A Q$ at different magnifications.

Figure 11. SEM images of $O A Q$ at different magnifications.

Figure 12. Kinetic behaviors of monomer $A Q$, product $O A Q$ and antioxidant standard (Trolox) 


\section{Table 1}

\begin{tabular}{|c|c|c|c|}
\hline & $\mathrm{EC}_{50}(\mu \mathrm{g} / \mathrm{ml})$ & $T E C_{50}$ (hour) & $\operatorname{AE}\left(x_{10}^{-3}\right)$ \\
\hline $\mathbf{A Q}$ & $91.594 \pm 0.78^{\mathrm{c}}$ & $10.14 \pm 0.17^{\mathrm{a}}$ & $1.076 \pm 0.03^{\mathrm{a}}$ \\
\hline OAQ & $49.149 \pm 1.03^{b}$ & $9.09 \pm 0.06^{\mathrm{a}}$ & $2.238 \pm 0.02^{b}$ \\
\hline Trolox & $13.319 \pm 0.59^{\mathrm{a}}$ & $15.91 \pm 0.01^{\mathrm{b}}$ & $4.719 \pm 0.05^{\mathrm{c}}$ \\
\hline
\end{tabular}

$\mathrm{EC}_{50}$ : The concentration of the antiradical (AQ, OAQ or trolox) required to decrease the initial DPPH concentration by $50 \%$ was obtained by plotting the percentages of DPPH remaining against the concentration of the antiradical.

Each value is expressed as mean \pm standard error $(n=3)$ Means with different letters within a row are significantly different $(p<0.05)$. 


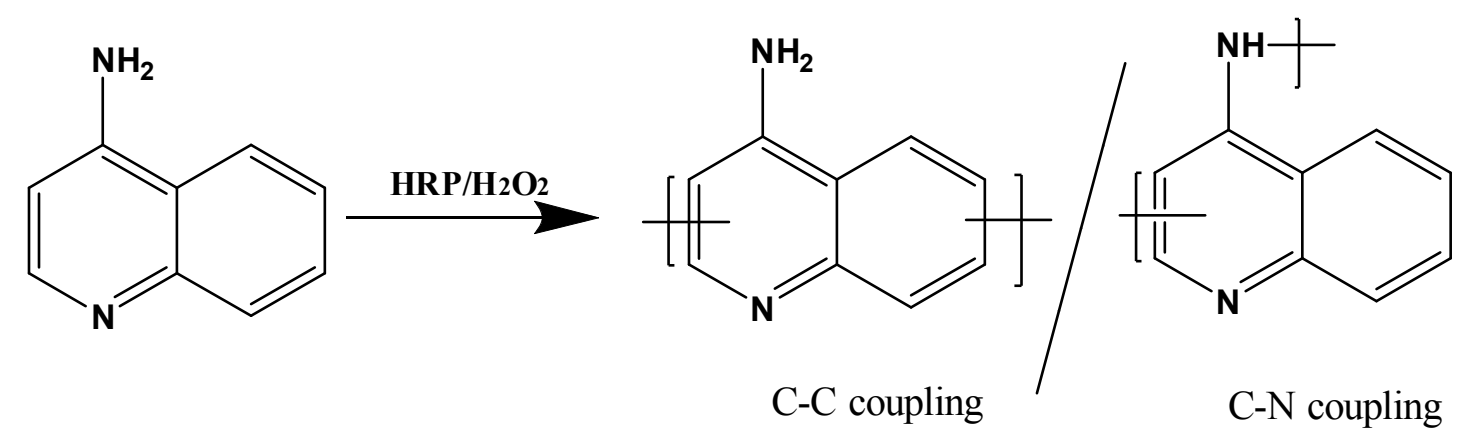

Figure 1.

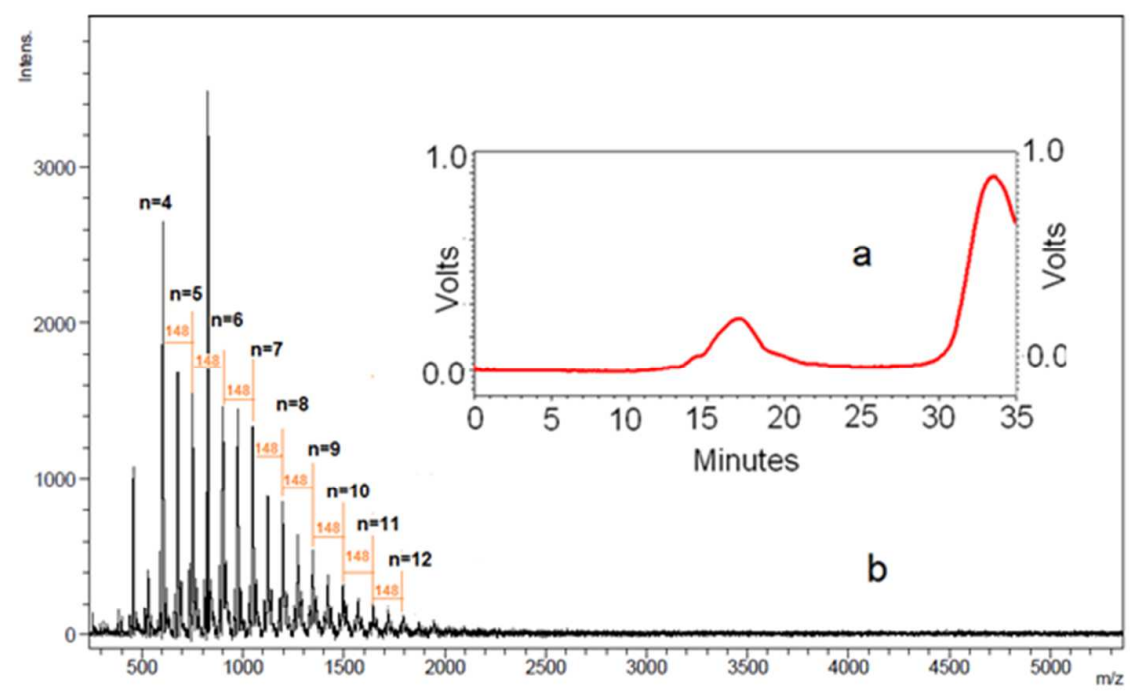

Figure 2. 


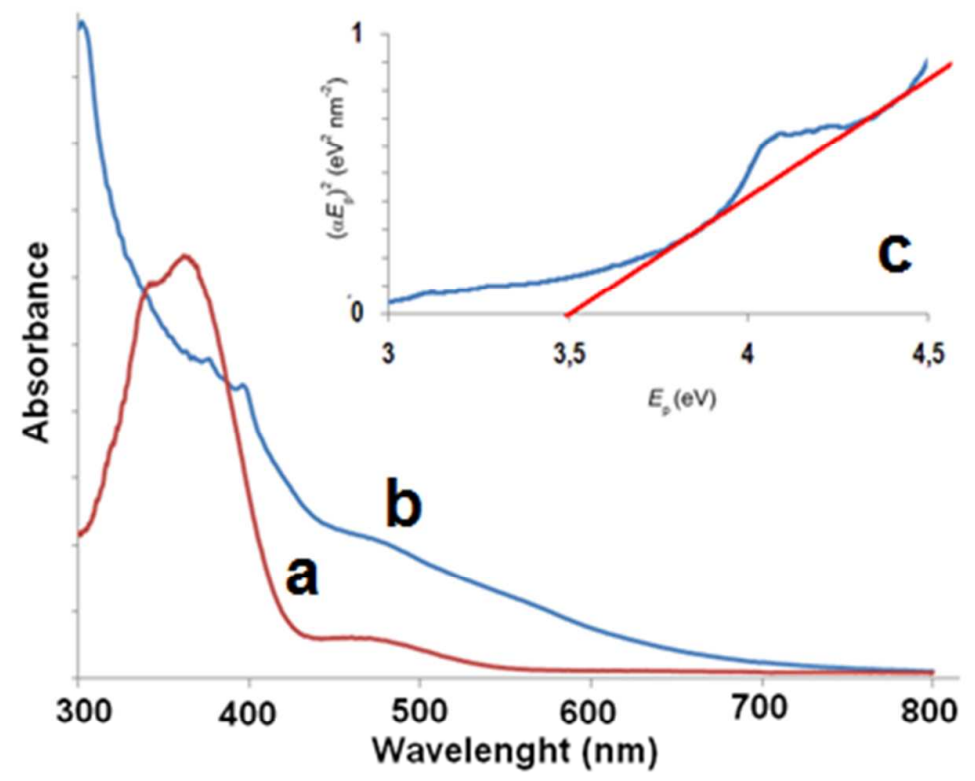

Figure 3.

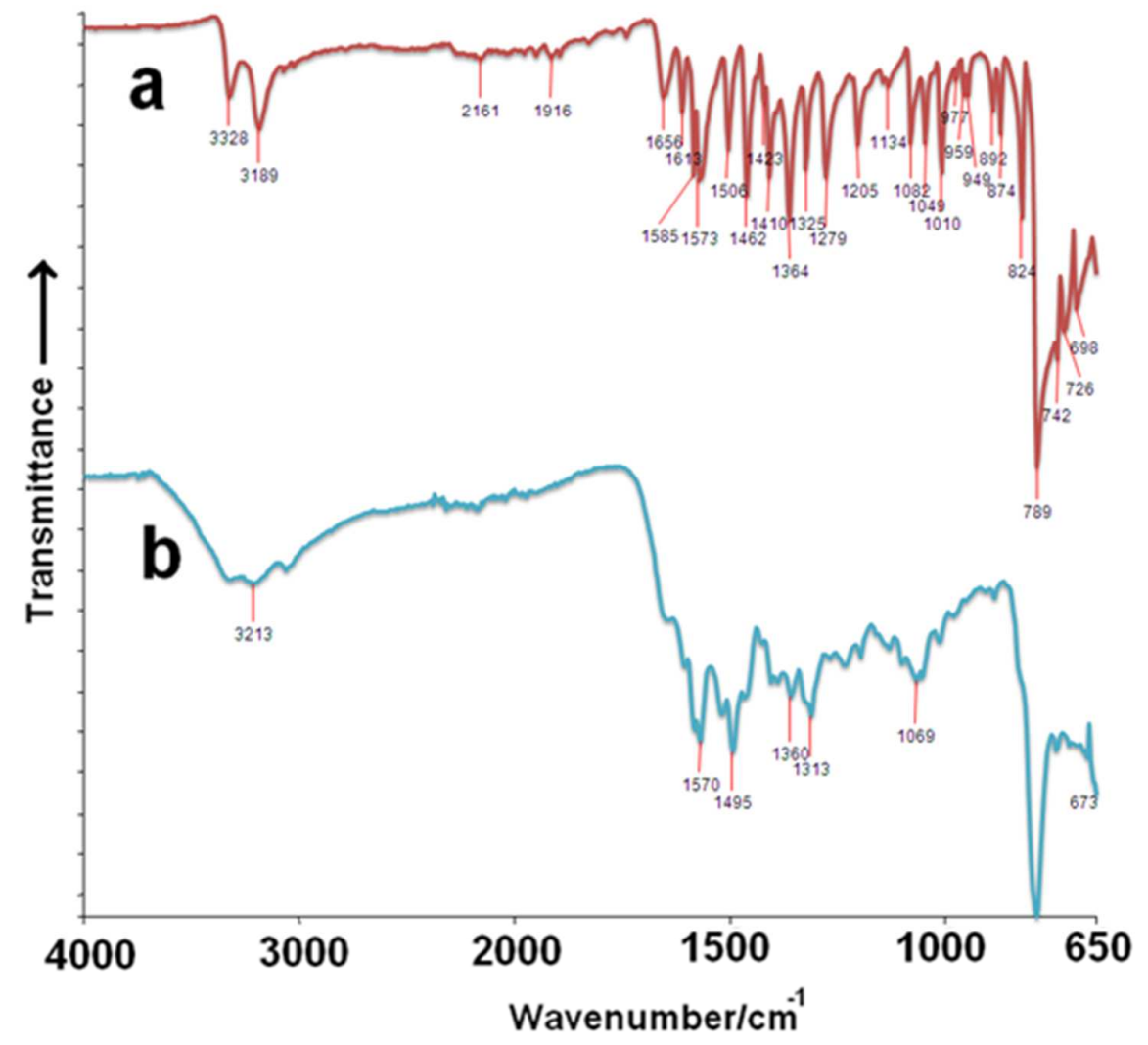

Figure 4. 

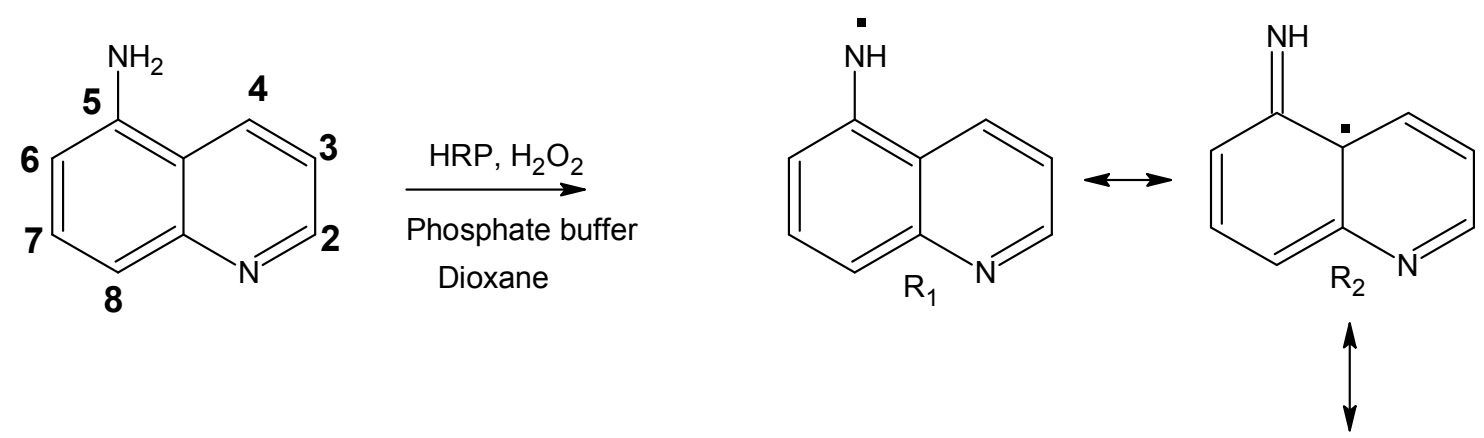

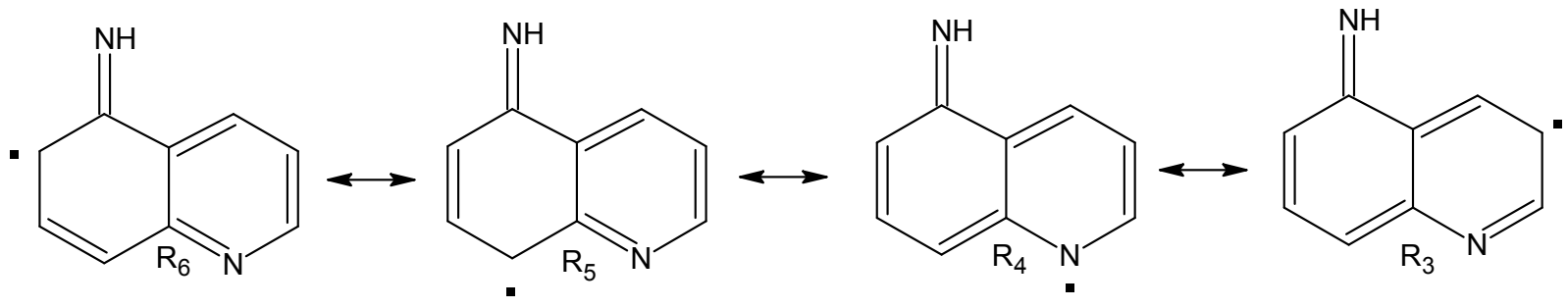

Figure 5.

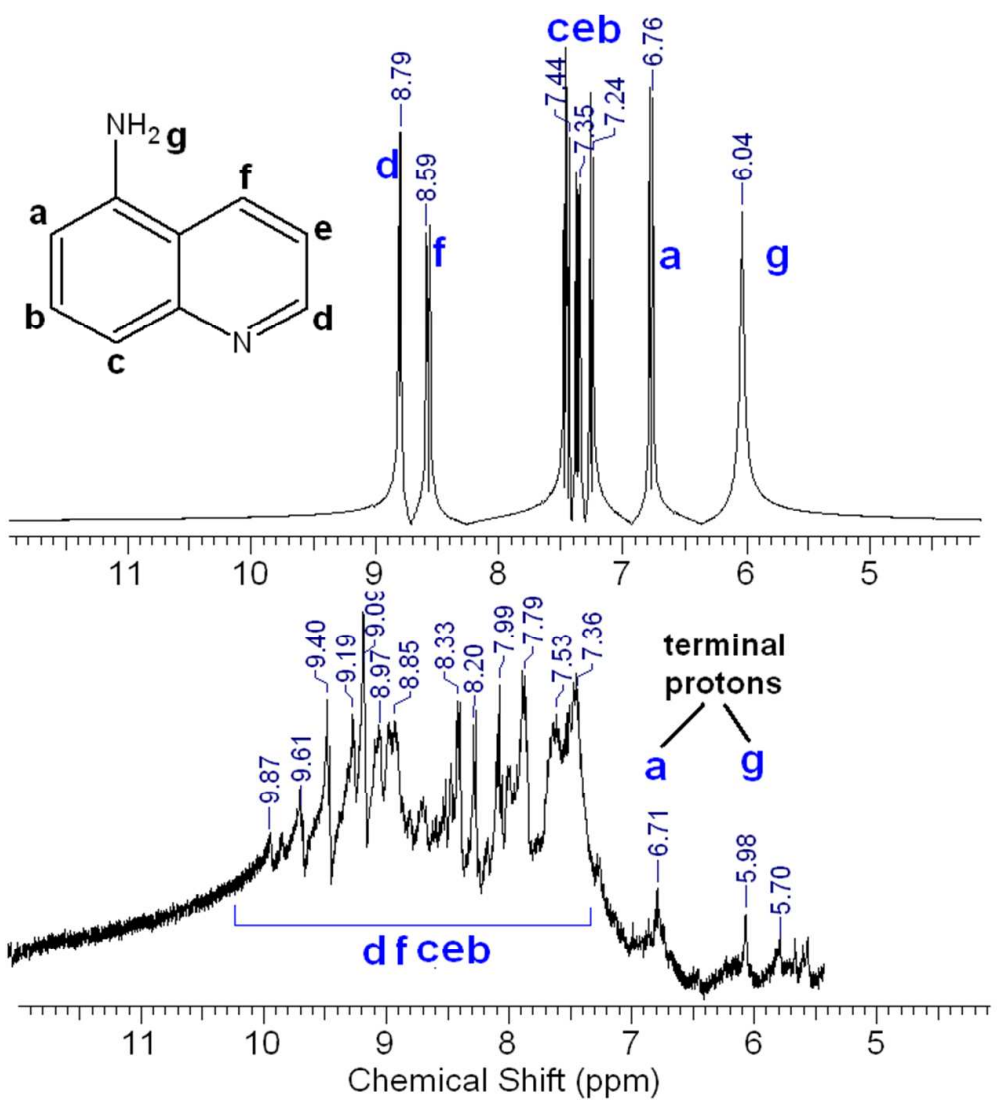

Figure 6. 

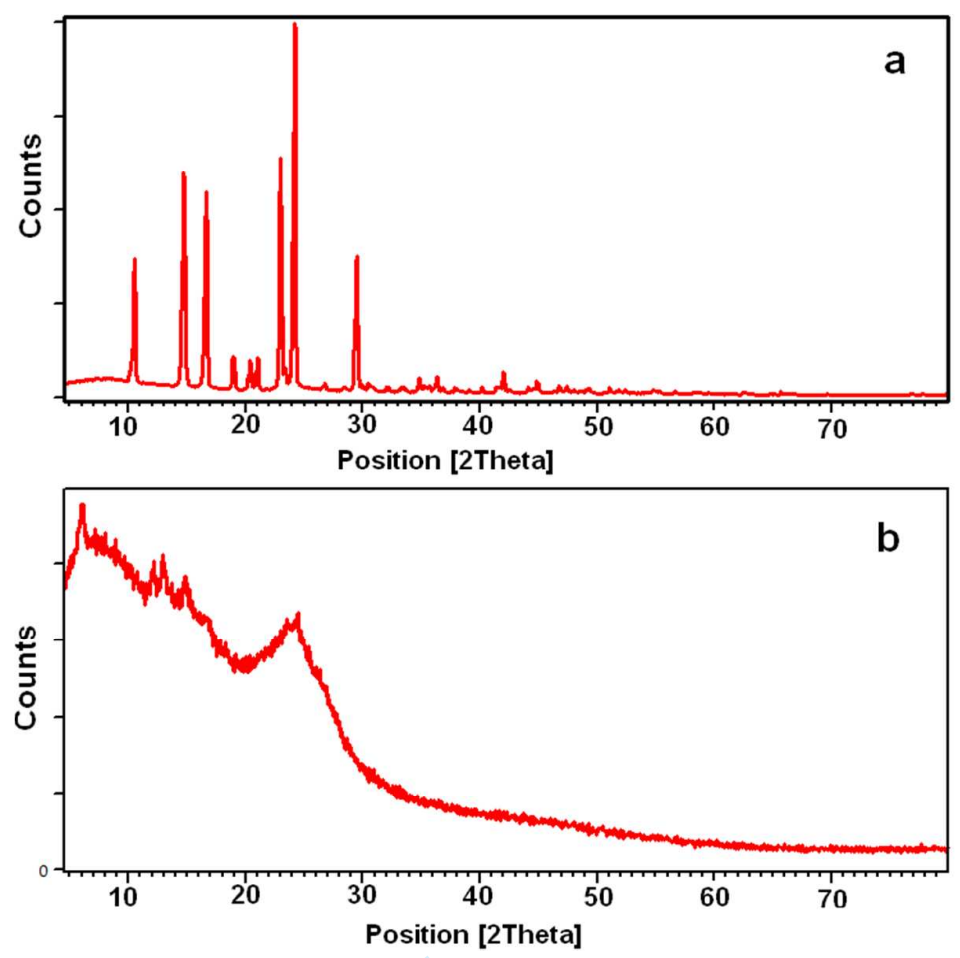

Figure 7.

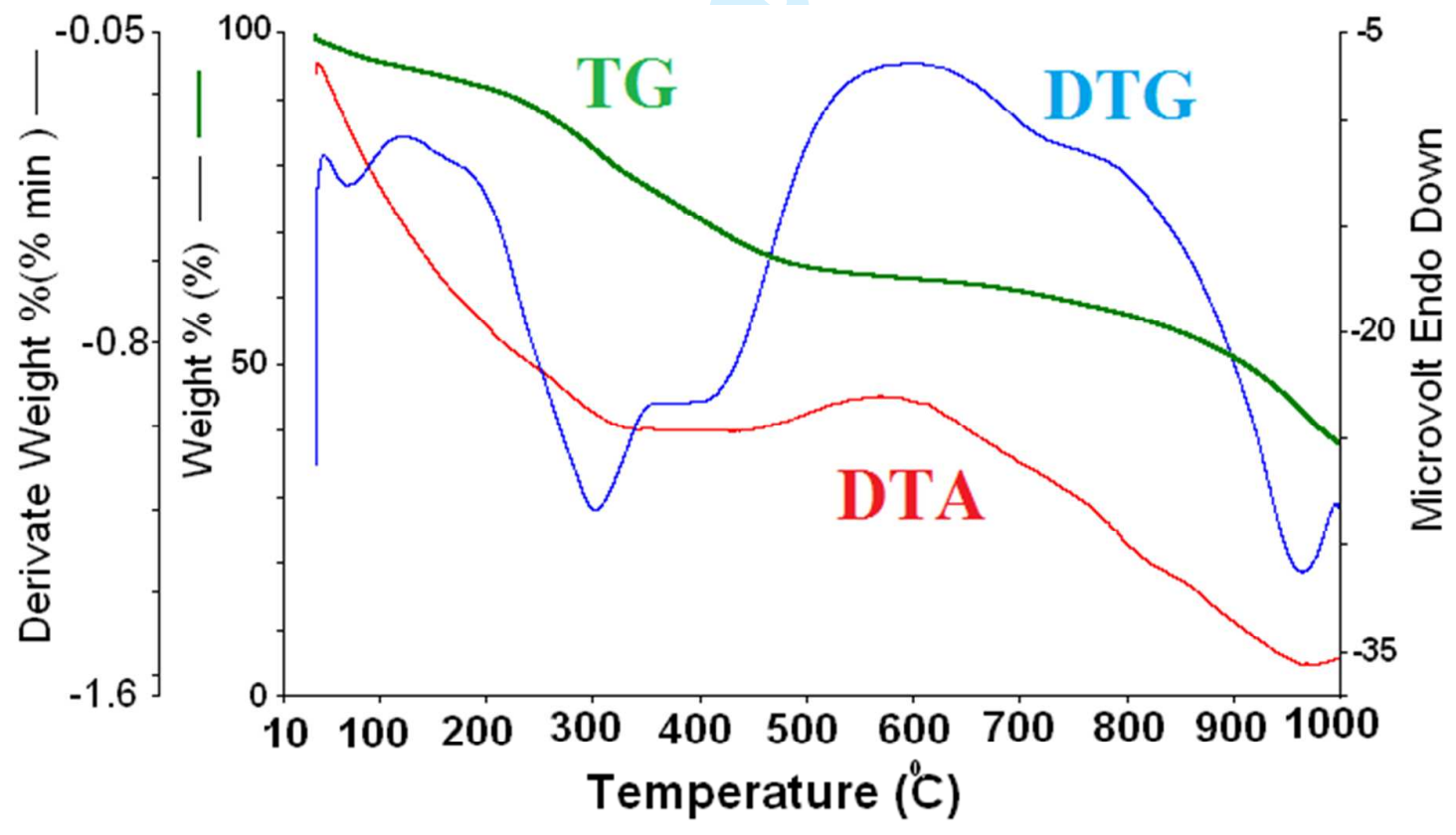

Figure 8. 


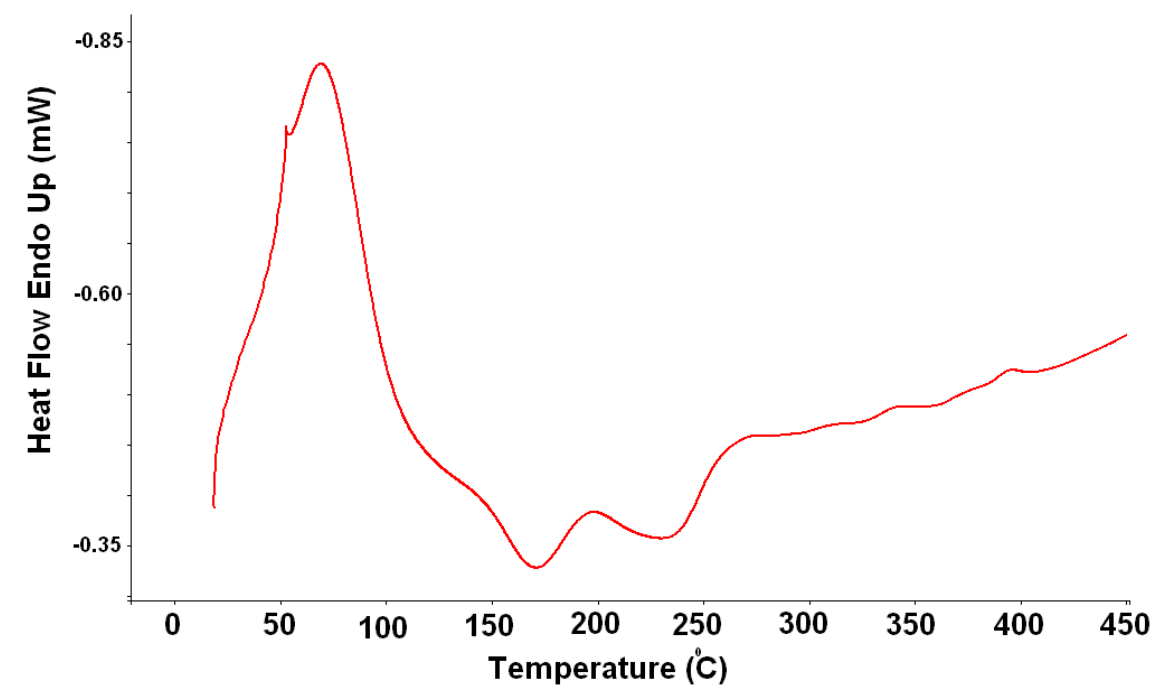

Figure 9. 

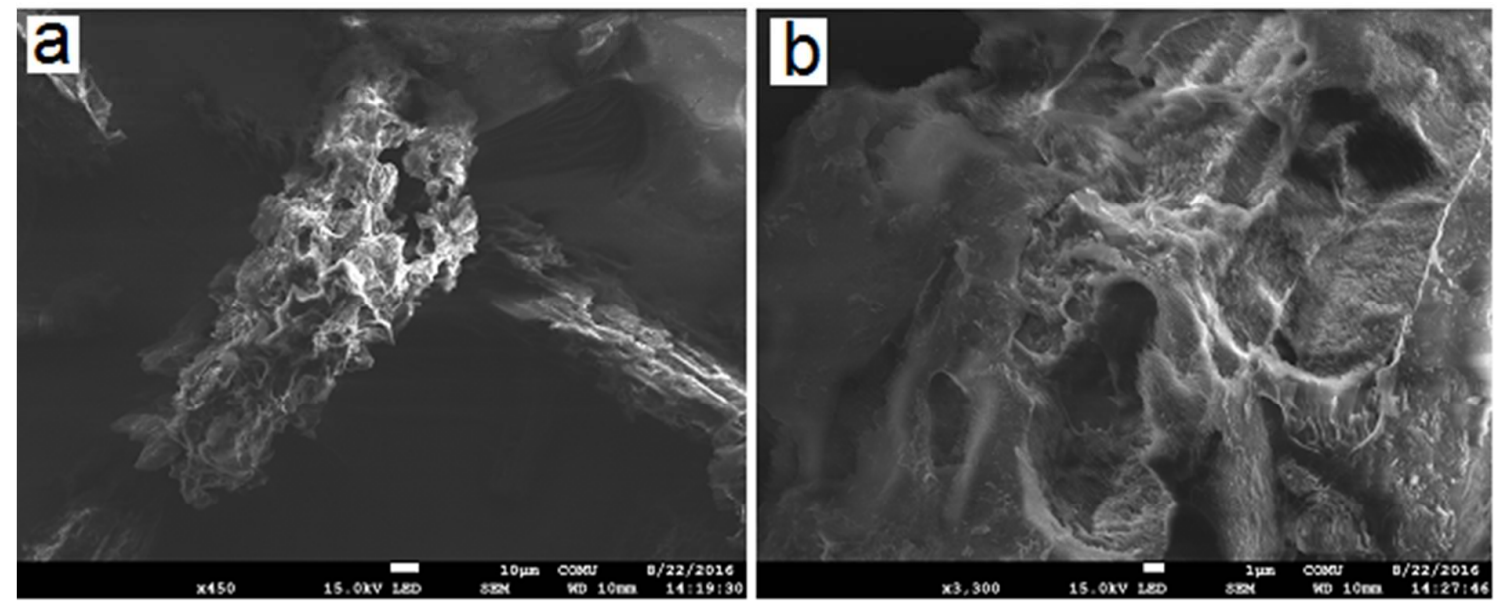

Figure 10.
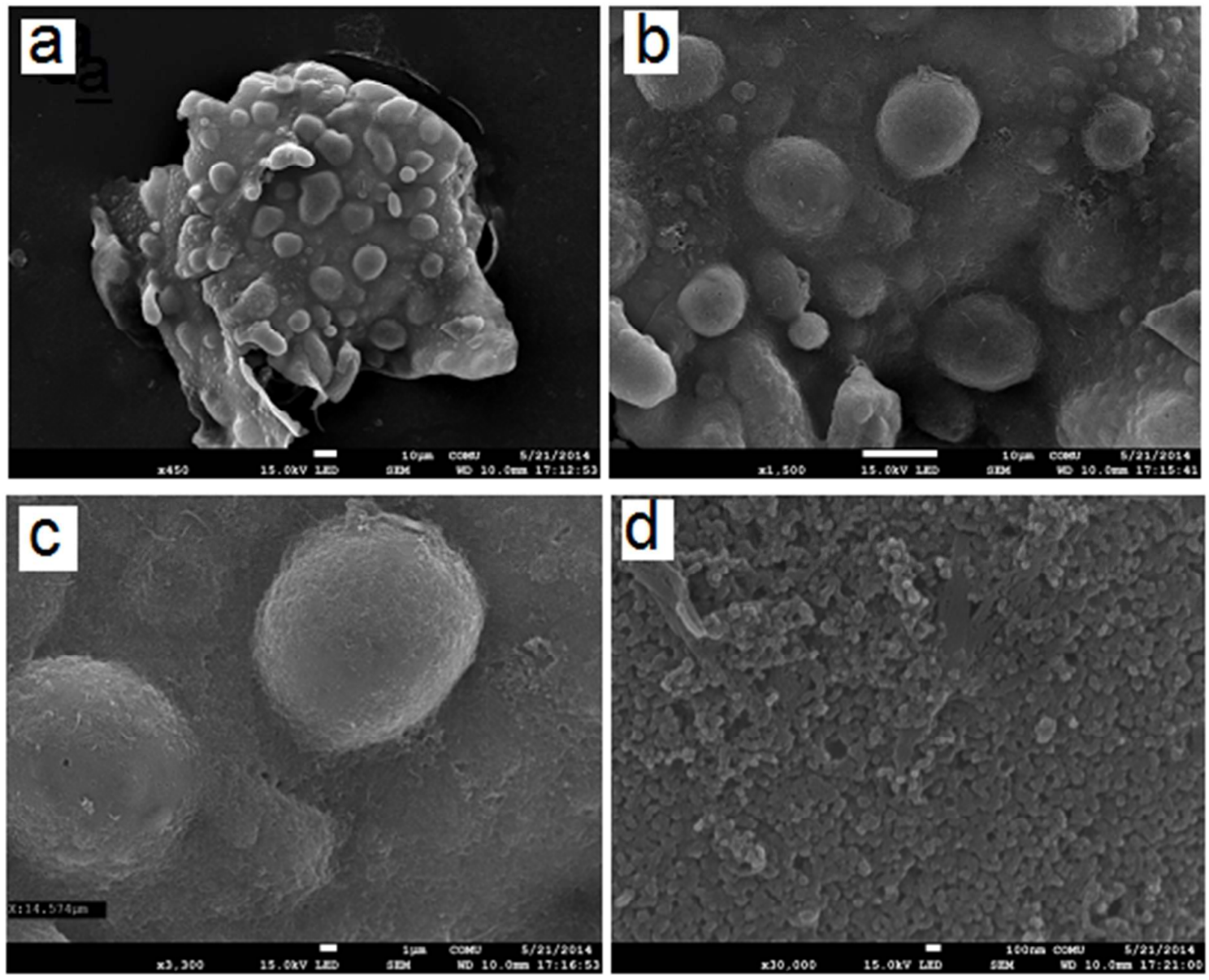

Figure 11. 

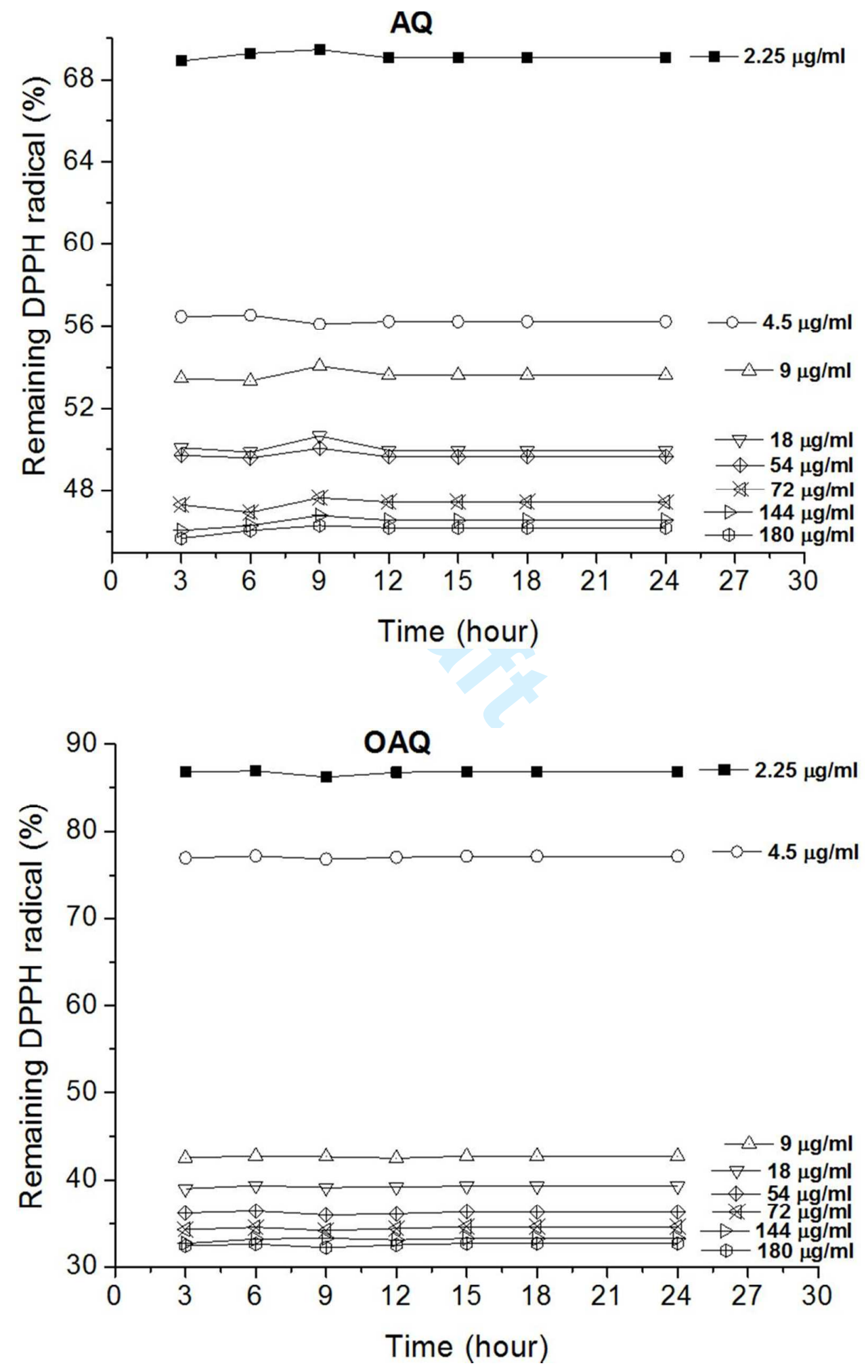


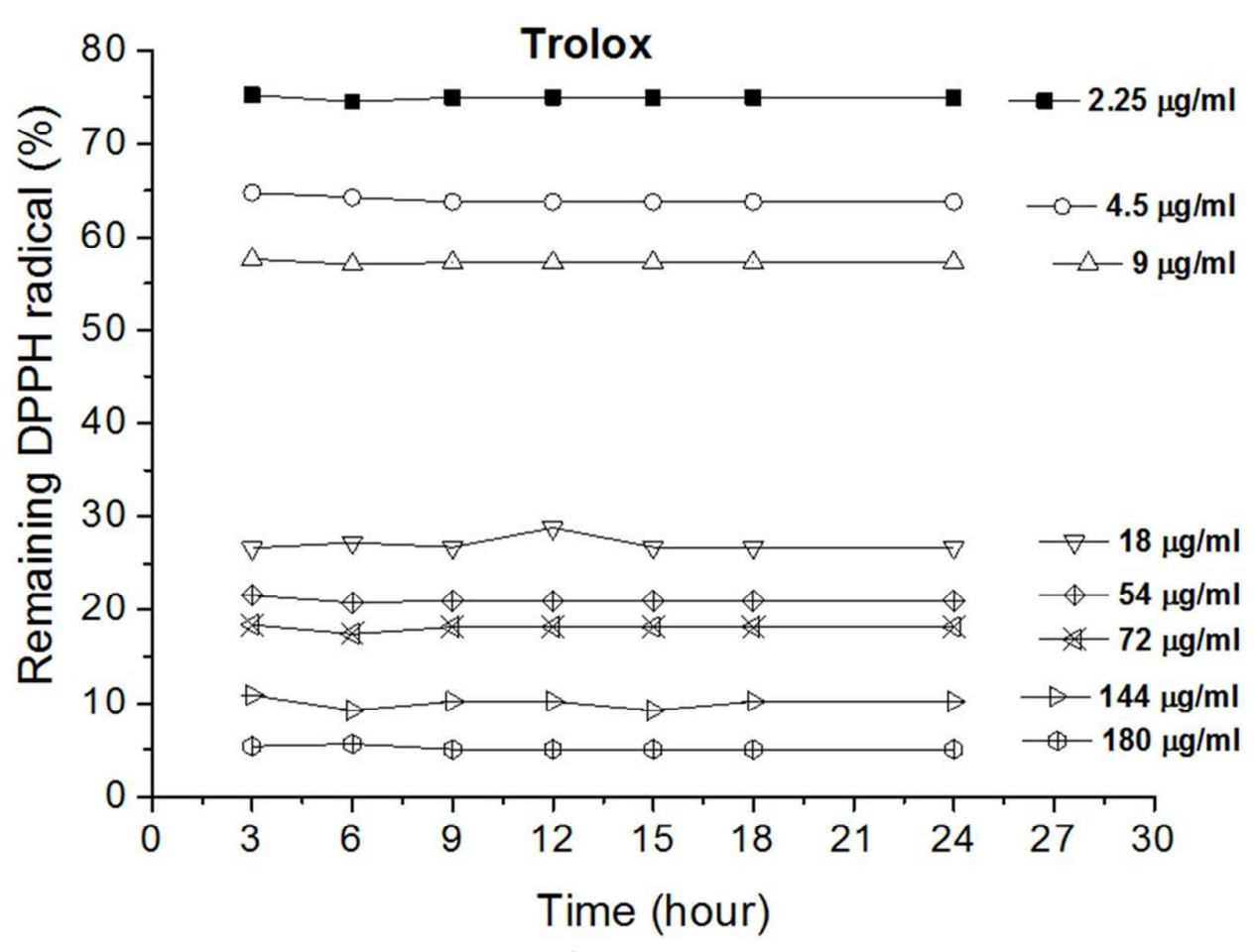

Figure 12. 